\title{
molecules
}

ISSN 1420-3049

www.mdpi.com/journal/molecules

Article

\section{In Vitro Antioxidant Properties of Flavonoids and Polysaccharides Extract from Tobacco (Nicotiana tabacum L.) Leaves}

\author{
Qiao-Mei Ru, Li-Juan Wang, Wei-Ming Li, Jing-Lu Wang and Yu-Ting Ding * \\ College of Biological and Environmental Engineering, Zhejiang University of Technology, \\ Hangzhou 310032, China
}

* Author to whom correspondence should be addressed; E-Mail: dingyt@zjut.edu.cn; Tel./Fax: +86-571-8832-0237.

Received: 2 August 2012; in revised form: 11 September 2012 / Accepted: 12 September 2012 / Published: 21 September 2012

\begin{abstract}
In the present study, antioxidant properties of flavonoids and polysaccharides from tobacco (Nicotiana tabacum L.) leaves were evaluated in several in vitro systems, e.g., scavenging activities on hydroxyl, superoxide anion, 1,1-diphenyl-2-picrylhydrazyl (DPPH) and 2,2'-azino-bis(3-ethylbenzthiazoline-6-sulphonic acid) (ABTS) radicals, and reducing power. Flavonoids showed much better activity than polysaccharides in scavenging activities on free radicals. When compared to the positive control, ascorbic acid, both showed weaker antioxidant potential. However, flavonoids possessed comparable superoxide anion, DPPH and ABTS radical scavenging abilities to ascorbic acid at high concentration $(600 \mu \mathrm{g} / \mathrm{mL})$. Meanwhile, it was found that flavonoids had prominent effects on the reducing power, which was equivalent to ascorbic acid, and was significantly higher than polysaccharides. These results clearly indicate that flavonoids are effective in scavenging free radicals and have the potential to be powerful antioxidants. Thus, tobacco leaves could be considered as a potential source of natural antioxidants for food, pharmaceutical, cosmetics or nutraceutical industries.
\end{abstract}

Keywords: tobacco (Nicotiana tabacum L.) leaves; flavonoids; polysaccharides; reducing power 


\section{Introduction}

In China, tobacco (Nicotiana tabacum L.) is a very important economic crop. Tobacco leaf production in China was about 2.5 million tons in 2008, representing an increase in production of $22.9 \%$ compared with that in 2007 [1]. However, over $20 \%$ of tobacco resources are discarded as processing waste, which pollutes the environment and cause a big waste issue. In fact, the discarded tobacco leaves are economically valuable because of abundant bioactive compounds in them, such as polyphenols, proteins and aromatic compounds [1-3]. Therefore, it is important to investigate and better utilize the tobacco leaves resource. Wang et al. [4] identified the polyphenols in tobacco leaves and their antioxidant and antimicrobial activities were also investigated.

Flavonoids, very important constituents of plants, may contribute directly to anti-oxidative action because of the scavenging ability conferred by their hydroxyl groups. It was well document that polyphenolic compounds have inhibitory effects on mutagenesis and carcinogenesis in humans when up to $1 \mathrm{~g}$ daily is consumed from a diet rich in fruits and vegetables [5]. Interest in phenolics is increasing in the food industry because of their ability to retard oxidative degradation of lipids, thereby improving the quality and nutritional value of foods [6]. Polysaccharides are composed of 100 or more monosaccharides and often present in plants. As naturally occurring biological constituents, these high molecular weight polymers are highly appreciated for their multipurpose therapeutic properties, such as antitumor, immune-modulating, anti-flammatory, anti-pathogens, and antioxidant activities [7]. Thus, it would be beneficial to isolate polysaccharides from tobacco leaves for using as a nutritional supplement. Therefore, the basic aim of this research was to study antioxidant properties of flavonoids and polysaccharides from tobacco leaves.

\section{Results and Discussion}

\subsection{Flavonoids and Polysaccharides from Tobacco Leaves}

The yields of flavonoids and polysaccharides from tobacco leaves on a dry weight basis were $10.83 \pm 0.91 \mathrm{mg} \mathrm{RE} / \mathrm{g}$ and $49.82 \pm 3.42 \mathrm{mg} / \mathrm{g}$, respectively. For the polysaccharidic fraction, a level of $46.61 \pm 3.11 \mathrm{mg} / \mathrm{g}$ was shown for the neutral polysaccharide, whereas $3.21 \pm 0.22 \mathrm{mg} / \mathrm{g}$ was found for the acidic polysaccharides. The total phenolic contents of the flavonoid and polysaccharidic fractions were investigated, which were $23.2 \pm 1.31$ and $0.74 \pm 0.04 \mathrm{mg} \mathrm{GAE} / \mathrm{g}$, respectively. It was confirmed that some polysaccharides are linked to phenols, and might be co-extracted using polar solvents [8]. Wang et al. [4] characterized rutin and chlorogenic acid as the two main polyphenol compounds in tobacco leaves.

\subsection{Scavenging Ability on Hydroxyl Radicals}

The scavenging effects of flavonoids and polysaccharides on hydroxyl radicals are shown in Figure 1. It was noticed that ascorbic acid showed the most pronounced effect, followed by flavonoids and polysaccharides. The present results proved that flavonoids was a good scavenger for hydroxyl radicals. Wang et al. [9] reported that a rutin standard showed much higher inhibition effect than acidic flavonoids and neutral flavonoids from Lycium barbarum L. The high antioxidant activity of flavonoids can be attributed to hydroxy groups in the A- and B-rings in rutin, and the greater the 
number of hydroxy groups, the higher is the capacity to scavenge free radicals [10]. Moreover, neutral polysaccharides exhibited much poor scavenging effect than acid polysaccharides in L. barbarum L. [9].

Figure 1. Scavenging ability of flavonoids and polysaccharides of tobacco leaves on hydroxyl radicals. Data are means \pm standard deviation of triplicate experiments.

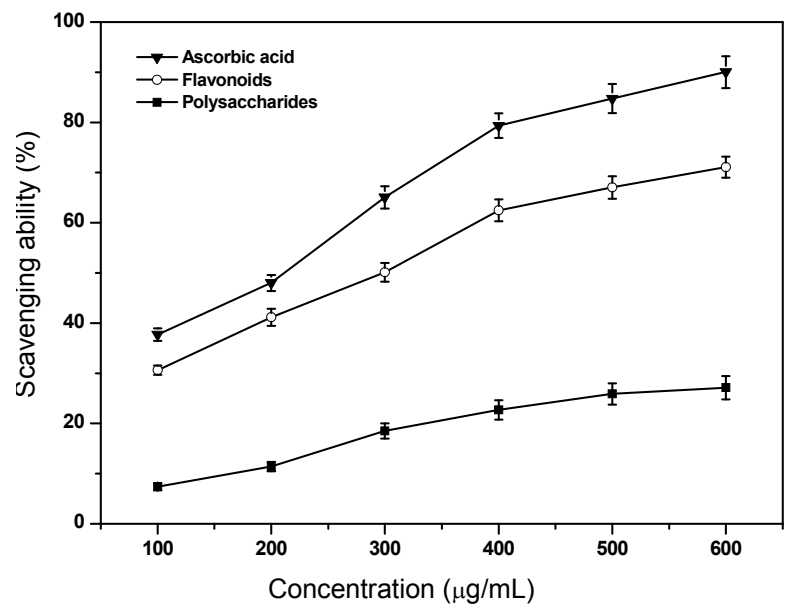

\subsection{Scavenging Ability on Superoxide Anion Radicals}

The effects of flavonoids and polysaccharides on superoxide anion radicals were determined and the results are shown in Figure 2. For the control treatment, the scavenging effect of ascorbic acid was substantially higher than those of flavonoids and polysaccharides $(p<0.05)$. However, flavonoids possessed comparable radical scavenging abilities with ascorbic acid when the tested concentration was at $600 \mu \mathrm{g} / \mathrm{mL}(p>0.05)$. Flavonoids were effective scavengers for superoxide anion radicals, and could be advantageous for preventing injury induced by superoxide radicals in pathological conditions. A similar phenomenon was also observed in L. barbarum L. [9]. For flavonoids, the keto group at C-4' and hydroxy group at C-3' or C-5' of the C-ring were effective in scavenging superoxide anion, and the greater the number of hydroxy groups, the better is the scavenging activity [11]. Meanwhile, the hydroxy groups in the A- and B-rings in rutin should contribute to this effect due to their hydrogen donation ability [12].

Figure 2. Scavenging ability of flavonoids and polysaccharides of tobacco leaves on superoxide anion radicals. Data are means \pm standard deviation of triplicate experiments.

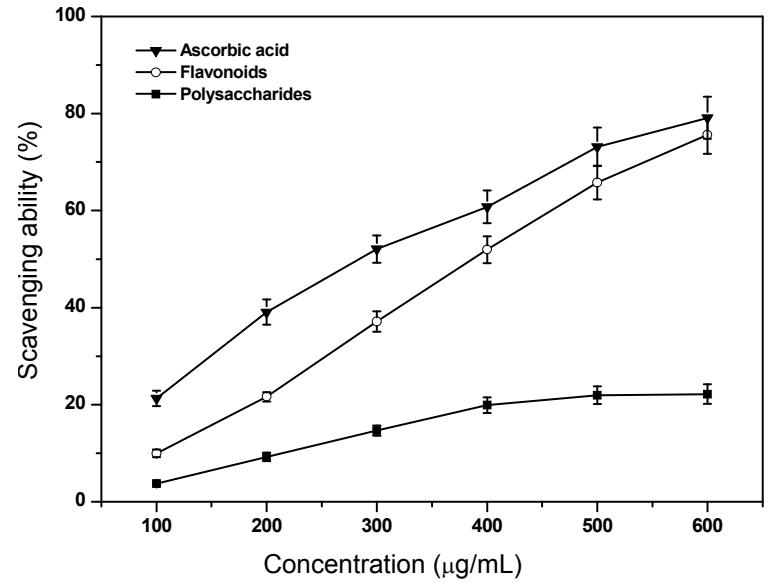




\subsection{Scavenging Ability on DPPH Radicals}

Figure 3 shows the scavenging effects of flavonoids and polysaccharides on DPPH free radicals. As expected, flavonoids exhibited a strong ability to quench DPPH radicals, and the DPPH radical scavenging activity of flavonoids at high concentration $(600 \mu \mathrm{g} / \mathrm{mL})$ was parallel to that of ascorbic acid $(p>0.05)$. This indicated that flavonoids were good antioxidants with strong DPPH radical scavenging activity. This result is in good agreement with that of Dziri et al. [13], who reported that the antioxidant activity of rosy garlic in the DPPH test was mainly attributable to flavonoids. In Ganoderma lucidum from Northeastern Portugal, a high linear correlation between the DPPH scavenging activity of phenolic extracts and total phenolic contents were demonstrated [14]. The acidic polysaccharides showed a larger DPPH free radical-scavenging activity than did the neutral polysaccharides in L. barbarum L. [9], which should be due to the ability of galacturonic acid present in the former to chelate metal ion and in turn scavenge DPPH radical. Asker et al. [15] isolated acidic polysaccharide from Bacillus polymyxa NRC-A and found that the antioxidant activity of polysaccharide was correlated with the content of galacturonic acid.

Figure 3. Scavenging ability of flavonoids and polysaccharides of tobacco leaves on DPPH radicals. Data are means \pm standard deviation of triplicate experiments.

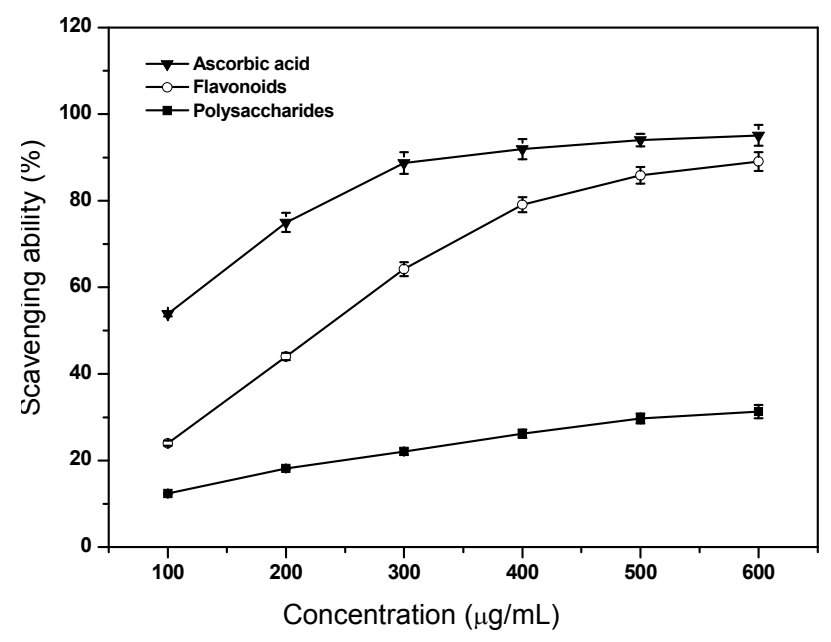

\subsection{Scavenging Ability on ABTS Radicals}

Figure 4 reveals the scavenging abilities of flavonoids and polysaccharides of tobacco leaves on ABTS radicals. As shown for ABTS scavenging, these data indicated the higher capacity of flavonoids to quench ABTS as compared to the polysaccharides $(p<0.05)$, and was parallel to ascorbic acid at high concentration $(600 \mu \mathrm{g} / \mathrm{mL}, p>0.05)$. These results are consistent with those of Wang et al. [9]. According to Oszmianski et al. [16], the antioxidant activities against DPPH or ABTS radicals were correlated with the concentration, chemical structures, and polymerization degrees of organ antioxidants. 
Figure 4. Scavenging ability of flavonoids and polysaccharides of tobacco leaves on ABTS radicals. Data are means \pm standard deviation of triplicate experiments.

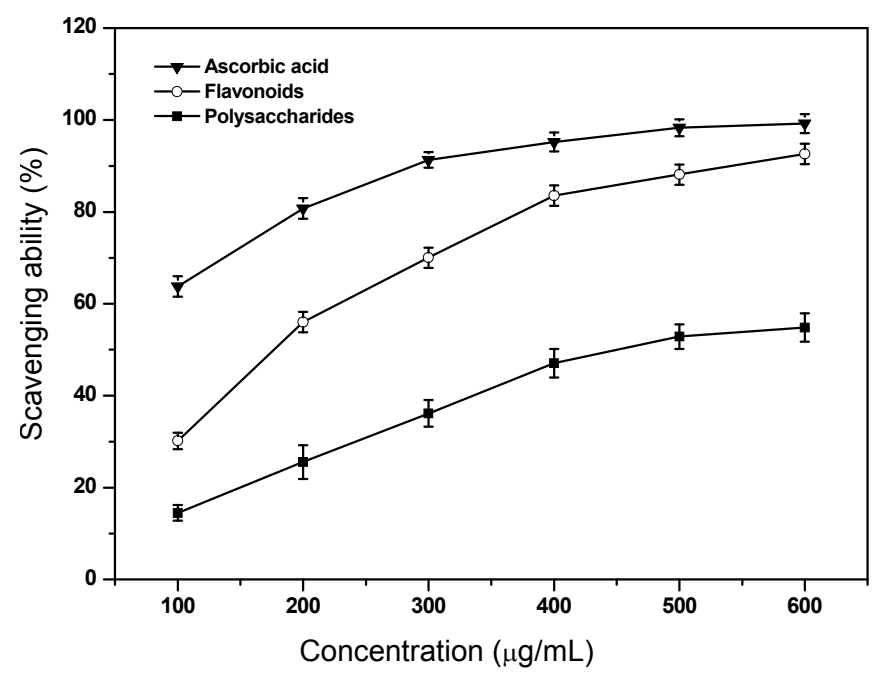

\subsection{Reducing Power Ability}

Figure 5 describes the reducing power of flavonoids and polysaccharides of tobacco leaves. As can be seen, flavonoids showed the same antioxidant property as ascorbic acid $(p>0.05)$, indicating that flavonoids were effective as an antioxidant. High reducing power of flavonoids suggested their remarkable potency to donate electrons to reactive free radicals, thus converting them into more stable non-reactive species and finally terminate the free radical chain reaction [17]. However, polysaccharides were still less effective than flavonoids $(p<0.05)$. Our data is consistent with the previous study of Wang et al. [9]. It was confirmed that the hydroxy groups at C-3' and C-4' of the B-ring to be more active in reducing iron concentration [18]. In this study, the flavonoid fraction contained rutin, which belong to the flavonols and the presence of a catechol group in the B-ring should contribute to the reducing power of tobacco leaves. In G. lucidum from Northeastern Portugal, the low linear correlation between the reducing power and total polysaccharides content was provided, whereas considering phenolic contents obtained in polysaccharidic extract, the linear correlation with antioxidant activity increased [14].

Figure 5. Reducing power of flavonoids and polysaccharides of tobacco leaves. Data are means \pm standard deviation of triplicate experiments.

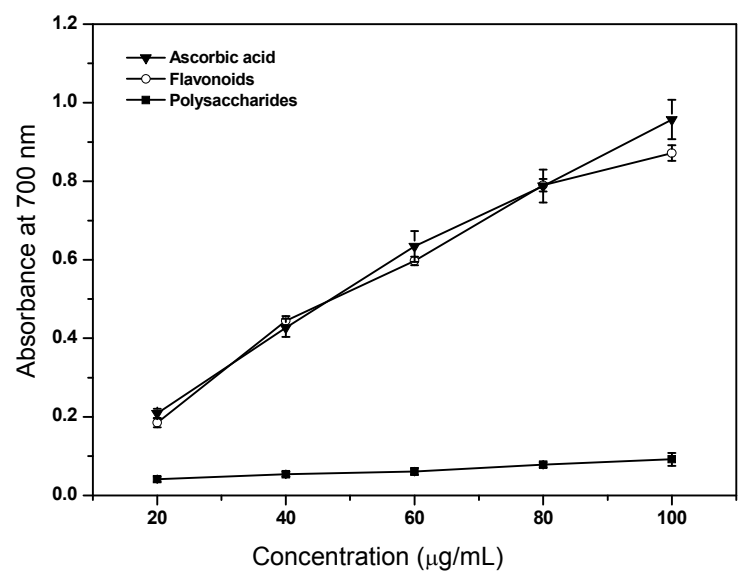




\section{7. $E C_{50}$ Values for Antioxidant Properties}

Concentration of sample at which the inhibition percentage reaches $50 \%$ is the $\mathrm{EC}_{50}$ value. The $\mathrm{EC}_{50}$ values of flavonoids and polysaccharides for free radical scavenging activities, as well as reducing power abilities, are summarized in Table $1 . \mathrm{EC}_{50}$ values of flavonoids for scavenging activities on hydroxyl, superoxide anion, DPPH and ABTS radicals were 305, 390, 235 and $175 \mu \mathrm{g} / \mathrm{mL}$, respectively, which were lower than those of polysaccharides (all $>600 \mu \mathrm{g} / \mathrm{mL})$. The $\mathrm{EC}_{50}$ value of flavonoids $(47 \mu \mathrm{g} / \mathrm{mL})$ for reducing power was similar with the control, ascorbic acid, and was significantly higher than that of polysaccharides $(>100 \mu \mathrm{g} / \mathrm{mL})$. Our results agreed with the findings of Ramos et al. [19] who found that the antioxidant activity of onion extracts was mainly attributable to flavonoids.

Table 1. $\mathrm{EC}_{50}$ values of flavonoids and polysaccharides of tobacco leaves.

\begin{tabular}{lccc}
\hline \multirow{2}{*}{ Test } & \multicolumn{3}{c}{ EC $_{\mathbf{5 0}}$ value $(\boldsymbol{\mu g} \mathbf{g} \mathbf{m L})$} \\
\cline { 2 - 4 } & Flavonoids & Polysaccharides & Ascorbic acid \\
\hline Scavenging ability on hydroxyl radicals & 305 & $>600$ & 210 \\
Scavenging ability on superoxide radicals & 390 & $>600$ & 285 \\
Scavenging ability on DPPH radicals & 235 & $>600$ & $>100$ \\
Scavenging ability on ABTS radicals & 175 & $>600$ & $>100$ \\
Reducing power & 47 & $>100$ & 47 \\
\hline
\end{tabular}

$\mathrm{EC}_{50}$ value is negatively related to the antioxidant activity, as it expresses the amount of antioxidant needed to decrease the radical concentration by $50 \%$. The lower the $\mathrm{EC}_{50}$ value, the higher is the antioxidant activity of the tested sample. Sun et al. [5] have reported the antioxidant properties of flavonoids from persimmon (Diospyros kaki L.) leaves, a traditional Chinese medicine, and indicated that the $\mathrm{EC}_{50}$ values for hydroxyl, superoxide and $\mathrm{DPPH}$ radical-scavenging ability were $70.64 \mu \mathrm{g} / \mathrm{mL}$, $41.58 \mu \mathrm{g} / \mathrm{mL}$ and $96.36 \mu \mathrm{g} / \mathrm{mL}$, respectively, which were much lower than that of flavonoids from tobacco leaves. However, the $\mathrm{EC}_{50}$ values for hydroxyl and superoxide anion radical-scavenging ability of flavonoids obtained by an ethanol extraction method from sweet potato (Ipomoea batatas L.) leaves, one of the most important economic crops, were about $0.8 \mathrm{mg} / \mathrm{mL}$ and $1.2 \mathrm{mg} / \mathrm{mL}$, respectively [20], indicating much weaker antioxidant ability than the flavonoids in this experiment. In addition, with regard to reducing power, the flavonoids showed higher ability than phenolic and polysaccharidic extracts of a popular medicinal mushroom, G. lucidum fruiting body, which were $0.62 \mathrm{mg} / \mathrm{mL}$ and $0.81 \mathrm{mg} / \mathrm{mL}$, respectively. Therefore, it was indicatative that flavonoids from tobacco leaves are effective in scavenging free radicals and have the potential to be a powerful antioxidant.

\section{Experimental}

\subsection{Materials and Chemicals}

Tobacco leaves were provided by China Tobacco Gansu Industrial Co., Ltd., dried at $70{ }^{\circ} \mathrm{C}$ in an oven and ground to obtain fine powder (50 mesh). Ascorbic acid, ABTS, DPPH, chlorogenic acid (95\% purity) and rutin (95\% purity) were purchased from Sigma Chemical Co. (St. Louis, MO, USA). All other chemicals were analytical grade and purchased from Shanghai Boer Chemical Reagent Co., Ltd. (Shanghai, China). 


\subsection{Isolation of Polysaccharides}

The polysaccharides of tobacco leaves was isolated according to the method described by He et al. [21] and Zhang et al. [22] with a minor modification. Tobacco leaves powder (50 g) was extracted with 20 volumes of distilled water at $100{ }^{\circ} \mathrm{C}$ for $2 \mathrm{~h}$. The suspension was centrifuged $(8,000 \times g)$ for $15 \mathrm{~min}$, and the supernatant was concentrated under vacuum. The protein in the product of condensation was deproteinized using the Sevag reagent [23]. After removal of the Sevag reagent, four volumes of anhydrous ethanol were added to this concentrate, and the mixture was stirred at room temperature for $20 \mathrm{~min}$ and then left at $4{ }^{\circ} \mathrm{C}$ overnight. The precipitate was collected by centrifugation $(8,000 \times g)$ for $15 \mathrm{~min}$, subsequently washed three times with anhydrous ethanol, acetone and ether, respectively, then dissolved in distilled water and dialyzed in dialysis bag (molecular weight cut-off, $12 \mathrm{kDa}$ ) against distilled water at room temperature for three successive days. The retained fraction was recovered, concentrated under vacuum and lyophilized to obtain crude polysaccharide. Crude polysaccharide was dissolved in distilled water, centrifuged, and then the supernatant was applied to a column of anion exchange chromatography on DEAE-Sepharose Fast Flow column $\left(100 \times 2.6 \mathrm{~cm}^{2}\right)$, eluting with $0-2 \mathrm{M}$ gradient $\mathrm{NaCl}$ solution. The fractions eluted with $0-2 \mathrm{M}$ gradient $\mathrm{NaCl}$ were collected, concentrated, dialyzed and lyophilized to get the purified polysaccharides.

\subsection{Quantitation of Polysaccharide Content}

The content of polysaccharides was determined using the phenol-sulphuric acid method [24]. Briefly, polysaccharide solution $(0.5 \mathrm{~mL})$ was mixed with phenol solution $(0.5 \mathrm{~mL}, 5 \%$, w/v $)$, followed by addition of concentrated sulphuric acid $(2.5 \mathrm{~mL})$ and shaking the mixture for $50 \mathrm{~min}$. The absorbance was measured at $490 \mathrm{~nm}$ and used to quantify polysaccharides, based on the standard curve of glucose $(10-1,000 \mu \mathrm{g} / \mathrm{mL})$.

\subsection{Isolation of Flavonoids}

Dried tobacco leaves powder $(50 \mathrm{~g})$ was placed in a reflux apparatus. Extraction was performed with $85 \%(\mathrm{v} / \mathrm{v})$ aqueous ethanol $(500 \mathrm{~mL})$ for $60 \mathrm{~min}$ at $80{ }^{\circ} \mathrm{C}$. The crude extract was filtered. The solution was concentrated under reduced pressure. The crude flavonoids-enriched extract was purified using a column $\left(25 \times 1.5 \mathrm{~cm}^{2}\right)$ packed with AB-8 macroporous adsorption resin according to the reference [25]. The conditions for purifying the flavonoids by AB-8 resin were: injecting concentration $3.75 \mathrm{mg} / \mathrm{mL}$, $\mathrm{pH}=5$, injecting velocity $2.0 \mathrm{~mL} / \mathrm{min}, 40 \%(\mathrm{v} / \mathrm{v})$ ethanol as desorption solvent, desorption velocity of flow $1.5 \mathrm{~mL} / \mathrm{min}$. The purified extract of flavonoids was collected and evaporated at $50{ }^{\circ} \mathrm{C}$, and was then freeze-dried for determination of flavonoid content and antioxidant property.

\subsection{Determination of Flavonoid Content}

The content of flavonoids was determined using a colormetric method described by Yi et al. [26] with several modifications. Briefly, diluted sample $(1 \mathrm{~mL})$ was mixed with $\mathrm{NaNO}_{2}(1 \mathrm{~mL}, 5 \%$, w/v). After $6 \mathrm{~min}, \mathrm{AlCl}_{3}(1 \mathrm{~mL}, 10 \%, \mathrm{w} / \mathrm{v})$ was added and allowed to stand for $6 \mathrm{~min}$, then $\mathrm{NaOH}(5 \mathrm{~mL}$, $4 \%, \mathrm{w} / \mathrm{v}$ ) was added to the mixture. Absorbance was taken at $510 \mathrm{~nm}$ after $15 \mathrm{~min}$. The content of flavonoids was expressed as rutin equivalents determined from a rutin calibration curve $(10-1,000 \mu \mathrm{g} / \mathrm{mL})$. 


\subsection{Determination of Total Phenolic Content}

Total phenolic content was measured by using the Folin-Ciocalteu reagent according to the method described [27] and using gallic acid as standard, with some modifications. Briefly, diluted extract $(0.5 \mathrm{~mL})$ was mixed with freshly diluted 10 -fold Folin-Ciocalteu reagent $(5.0 \mathrm{~mL})$. The mixture was allowed to react for $3 \mathrm{~min}$ and $7 \%$ aqueous solution of $\mathrm{Na}_{2} \mathrm{CO}_{3}(4.0 \mathrm{~mL})$ was added. The reaction mixture was kept in the dark for $2 \mathrm{~h}$ intermittent shacking and the absorbance was read at $760 \mathrm{~nm}$.

\subsection{Assay of Antioxidant Property}

\subsubsection{Scavenging Activity on Hydroxyl Radicals}

Hydroxyl radical scavenging activity was determined based on the method described by Smirnoff and Cumbes [28] with some modifications. The reaction mixture containing the tested sample $(1 \mathrm{~mL})$ was incubated with a solution containing orthophenanthroline $(1 \mathrm{~mL}, 5 \mathrm{mM})$, phosphate buffer (0.8 mL, $7.5 \mathrm{mM}, \mathrm{pH} 7.4)$ and $\mathrm{FeSO}_{4}(0.5 \mathrm{~mL}, 7.5 \mathrm{mM})$. Finally, $\mathrm{H}_{2} \mathrm{O}_{2}(0.5 \mathrm{~mL}, 8.8 \mathrm{mM})$ was added, and the reaction mixture was then incubated at $37^{\circ} \mathrm{C}$ for $1 \mathrm{~h}$. The absorbance of the resulting solution was measured spectrophotometrically at $532 \mathrm{~nm}$. The hydroxyl radical scavenging ability was calculated using the following formula: Scavenging ability $(\%)=\left(1-\mathrm{A}_{\text {sample }} / \mathrm{A}_{\text {control }}\right) \times 100$, where $\mathrm{A}_{\text {control }}$ is the absorbance of control without the tested sample, and $\mathrm{A}_{\text {sample }}$ is the absorbance in the presence of the tested sample. The tested sample concentration providing $50 \%$ inhibition $\left(\mathrm{EC}_{50}\right)$ was calculated from the graph of scavenging effect percentage against tested sample concentration. Ascorbic acid was used as reference compound.

\subsubsection{Scavenging Activity on Superoxide Anion Radicals}

The scavenging activity of superoxide anion radicals was assessed referring to the reference [29] with several modifications. A tube containing Tris- $\mathrm{HCl}$ buffer $(3 \mathrm{~mL}, 50.0 \mathrm{mM}, \mathrm{pH} 8.2)$ and tested sample $(1 \mathrm{~mL})$ was incubated in a water bath at $25{ }^{\circ} \mathrm{C}$ for $20 \mathrm{~min}$, then pyrogallic acid $(0.4 \mathrm{~mL}$, $5.0 \mathrm{mM})$ at the same temperature was added and proceed at $25^{\circ} \mathrm{C} . \mathrm{HCl}$ solution $(0.1 \mathrm{~mL}, 8.0 \mathrm{M})$ was used to terminate the reaction after $4 \mathrm{~min}$. The absorbance of the mixture was measured at $320 \mathrm{~nm}$. The scavenging ability of superoxide anion radicals and $\mathrm{EC}_{50}$ were calculated as Section 3.6.1. For comparison, ascorbic acid was used as positive control.

\subsubsection{Scavenging Activity on DPPH Radicals}

DPPH radical scavenging activity was measured according to Braca et al. [30]. Tested sample $(0.2 \mathrm{~mL})$ was added to methanolic DPPH solution $(2.8 \mathrm{~mL}, 0.1 \mathrm{mM})$, then shaken vigorously and left standing at room temperature for $30 \mathrm{~min}$ in the dark. The absorbance of the resulting solution was then measured at $517 \mathrm{~nm}$. The DPPH radical scavenging effect and $\mathrm{EC}_{50}$ were calculated as Section 3.6.1. Ascorbic acid was used for comparison. 


\subsubsection{Scavenging Activity on ABTS Radicals}

The scavenging activity against ABTS radicals $\left(\mathrm{ABTS}^{+}\right)$was measured using the method of Fellegrini et al. [31] with some modifications. $\mathrm{ABTS}^{+}$were produced by reacting ABTS solution $(7 \mathrm{mM})$ with potassium persulphate $(1.4 \mathrm{mM})$, and the mixture would be kept in the dark at room temperature for $12 \sim 16 \mathrm{~h}$. In the moment of use, the $\mathrm{ABTS}^{+}$solution was diluted with ethanol to an absorbance of $0.70 \pm 0.02$ at $734 \mathrm{~nm}$. Tested sample $(0.2 \mathrm{~mL})$ was added to $\mathrm{ABTS}^{+}$solution $(2.8 \mathrm{~mL})$ and mixed vigorously. After reaction at room temperature for $6 \mathrm{~min}$, the absorbance at $734 \mathrm{~nm}$ was measured. The ABTS radical scavenging effect and $\mathrm{EC}_{50}$ were calculated as Section 3.6.1. Ascorbic acid was used as reference compound.

\subsubsection{Reducing Power Ability}

The reducing power was assessed referring to the method described in literature [32] with slight modifications. Tested sample $(1 \mathrm{~mL})$ was mixed with sodium phosphate buffer $(2.5 \mathrm{~mL}, 0.2 \mathrm{M}$, $\mathrm{pH}$ 6.6) and $\mathrm{K}_{3} \mathrm{Fe}(\mathrm{CN})_{6}\left(2.5 \mathrm{~mL}, 1 \%\right.$, w/v), and the mixture was incubated at $50{ }^{\circ} \mathrm{C}$ for $20 \mathrm{~min}$. After that, TCA $(2.5 \mathrm{~mL}, 10 \%$, w/v) were added, and the mixture was centrifuged at 3,000 $\times \mathrm{g}$ for $10 \mathrm{~min}$. Upper layer fraction $(2.5 \mathrm{~mL})$ was mixed with deionized water $(2.5 \mathrm{~mL})$ and $\mathrm{FeCl}_{3}(0.5 \mathrm{~mL}, 0.1 \%$, w/v) and thoroughly mixed. The absorbance was measured at $700 \mathrm{~nm}$ and ascorbic acid was used as positive control. A higher absorbance indicates a higher reducing power. The tested sample concentration providing 0.5 of absorbance $\left(\mathrm{EC}_{50}\right)$ was calculated from the graph of absorbance registered at $700 \mathrm{~nm}$ against the correspondent tested sample concentration.

\subsection{Statistical Analysis}

In order to assure the accuracy of the experimental data, each experiment was performed in triplicate and the result was expressed as mean \pm standard deviation of three replications. $p$ vaule $<0.05$ was regarded as significant.

\section{Conclusions}

Scavenging activities on free radicals and reducing power were investigated for flavonoids and polysaccharides of tobacco leaves. The flavonoids showed the more pronounced effect in antioxidant activity than polysaccharides. From the above results, it appears important to develop natural antioxidants from tobacco leaves, and this may be a good way for extensively utilizing the tobacco resource.

\section{Acknowledgments}

We are grateful to Wei-Zhen Tang and Shao-Jing Yuan for assistance.

\section{References}

1. Zhang, X.; Gao, H.; Zhang, L.; Liu, D.; Ye, X. Extraction of essential oil from discarded tobacco leaves by solvent extraction and steam distillation, and identification of its chemical composition. Ind. Crop Prod. 2012, 39, 162-169. 
2. Ruiz, J.M.; Bretones, G.; Baghour, M.; Ragala, L.; Belakbir, A.; Romero, L. Relationship between boron and phenolic metabolism in tobacco leaves. Phytochemistry 1998, 48, 269-272.

3. Teng, Z.; Wang, Q. Extraction, identification and characterization of the water-insoluble proteins from tobacco biomass. J. Sci. Food Agric. 2012, 92, 1368-1374.

4. Wang, H.; Zhao, M.; Yang, B.; Jiang, Y.; Rao, G. Identification of polyphenols in tobacco leaf and their antioxidant and antimicrobial activities. Food Chem. 2008, 107, 1399-1406.

5. Sun, L.; Zhang, J.; Lu, X.; Zhang, L.; Zhang, Y. Evaluation to the antioxidant activity of total flavonoids extract from persimmon (Diospyros kaki L.) leaves. Food Chem. Toxicol. 2011, 49, 2689-2696.

6. Wojdyło, A.; Oszmiański, J.; Czemerys, R. Antioxidant activity and phenolic compounds in 32 selected herbs. Food Chem. 2007, 105, 940-949.

7. Han, X.-Q.; Wu, X.-M.; Chai, X.-Y.; Chen, D.; Dai, H.; Dong, H.-L.; Ma, Z.-Z.; Gao, X.-M.; $\mathrm{Tu}, \mathrm{P} .-\mathrm{F}$. Isolation, characterization and immunological activity of a polysaccharide from the fruit bodies of an edible mushroom, Sarcodon aspratus (Berk.) S. Ito. Food Res. Int. 2011, 44, 489-493.

8. Galanakis, C.M.; Tornberg, E.; Gekas, V. Recovery and preservation of phenols from olive waste in ethanolic extracts. J. Chem. Technol. Biotechnol. 2010, 85, 1148-1155.

9. Wang, C.C.; Chang, S.C.; Inbaraj, B.S.; Chen, B.H. Isolation of carotenoids, flavonoids and polysaccharides from Lycium barbarum L. and evaluation of antioxidant activity. Food Chem. 2010, 120, 184-192.

10. Kao, T.-H.; Chen, B.-H. Functional components in soybean cake and their effects on antioxidant activity. J. Agric. Food Chem. 2006, 54, 7544-7555.

11. Van Acker, S.A.B.E.; van den Berg, D.; Tromp, M.N.J.L.; Griffioen, D.H.; van Bennekom, W.P.; van der Vijgh, W.J.F.; Bast, A. Structural aspects of antioxidant activity of flavonoids. Free Radic. Biol. Med. 1996, 20, 331-342.

12. Zhishen, J.; Mengcheng, T.; Jianming, W. The determination of flavonoid contents in mulberry and their scavenging effects on superoxide radicals. Food Chem. 1999, 64, 555-559.

13. Dziri, S.; Hassen, I.; Fatnassi, S.; Mrabet, Y.; Casabianca, H.; Hanchi, B.; Hosni, K. Phenolic constituents, antioxidant and antimicrobial activities of rosy garlic (Allium roseum var. odoratissimum). J. Funct. Foods 2012, 4, 423-432.

14. Heleno, S.A.; Barros, L.; Martins, A.; Queiroz, M.J.R.P.; Santos-Buelga, C.; Ferreira, I.C.F.R. Fruiting body, spores and in vitro produced mycelium of Ganoderma lucidum from Northeast Portugal: A comparative study of the antioxidant potential of phenolic and polysaccharidic extracts. Food Res. Int. 2012, 46, 135-140.

15. Asker, M.M.S.; Mahmoud, M.G.; Ibrahim, G.S. Structural characterization and biological activity of acidic polysaccharide fractions isolated from Bacillus polymyxa NRC-A. J. Appl. Sci. Res. 2007, 3, 1170-1177.

16. Oszmianski, J.; Wolniak, M.; Wojdylo, A.; Wawer, I. Comparative study of polyphenolic content and antiradical activity of cloudy and clear apple juices. J. Sci. Food Agric. 2007, 87, 573-579.

17. Zha, X.-Q.; Wang, J.-H.; Yang, X.-F.; Liang, H.; Zhao, L.-L.; Bao, S.-H.; Luo, J.-P.; Xu, Y.-Y.; Zhou, B.-B. Antioxidant properties of polysaccharide fractions with different molecular mass extracted with hot-water from rice bran. Carbohyd. Polym. 2009, 78, 570-575.

18. Moran, J.F.; Klucas, R.V.; Grayer, R.J.; Abian, J.; Becana, M. Complexes of iron with phenolic compounds from soybean nodules and other legume tissues: Prooxidant and antioxidant properties. Free Radic. Biol. Med. 1997, 22, 861-870. 
19. Ramos, F.A.; Takaishi, Y.; Shirotori, M.; Kawaguchi, Y.; Tsuchiya, K.; Shibata, H.; Higuti, T.; Tadokoro, T.; Takeuchi, M. Antibacterial and antioxidant activities of quercetin oxidation products from yellow onion (Allium cepa) skin. J. Agric. Food Chem. 2006, 54, 3551-3557.

20. Huang, X.; Tu, Z.; Xiao, H.; Li, Z.; Zhang, Q.; Wang, H.; Hu, Y.; Zhang, L. Dynamic high pressure microfluidization-assisted extraction and antioxidant activities of sweet potato (Ipomoea batatas L.) leaves flavonoid. Food Bioprod. Process. 2012, in press.

21. He, J.-Z.; Ru, Q.-M.; Dong, D.-D.; Sun, P.-L. Chemical characteristics and antioxidant properties of crude water soluble polysaccharides from four common edible mushrooms. Molecules 2012, 17, 4373-4387.

22. Zhang, A.-Q.; Fu, L.; Xu, M.; Sun, P.-L.; Zhang, J.-S. Structure of a water-soluble heteropolysaccharide from fruiting bodies of Hericium erinaceus. Carbohyd. Polym. 2012, 88, 558-561.

23. Navarini, L.; Gilli, R.; Gombac, V.; Abatangelo, A.; Bosco, M.; Toffanin, R. Polysaccharides from hot water extracts of roasted Coffea arabica beans: Isolation and characterization. Carbohyd. Polym. 1999, 40, 71-81.

24. DuBois, M.; Gilles, K.A.; Hamilton, J.K.; Rebers, P.A.; Smith, F. Colorimetric method for determination of sugars and related substances. Anal. Chem. 1956, 28, 350-356.

25. Zhang, G.; He, L.; Hu, M. Optimized ultrasonic-assisted extraction of flavonoids from Prunella vulgaris L. and evaluation of antioxidant activities In Vitro. Innov. Food Sci. Emerg. 2011, 12, $18-25$.

26. Yi, Z.; Yu, Y.; Liang, Y.; Zeng, B. In vitro antioxidant and antimicrobial activities of the extract of Pericarpium Citri Reticulatae of a new Citrus cultivar and its main flavonoids. LWT-Food Sci. Technol. 2008, 41, 597-603.

27. Li, J.-E.; Nie, S.-P.; Qiu, Z.-H.; Che, M.-J.; Li, C.; Xie, M.-Y. Antimicrobial and antioxidant activities of the essential oil from Herba Moslae. J. Sci. Food Agric. 2010, 90, 1347-1352.

28. Smirnoff, N.; Cumbes, Q.J. Hydroxyl radical scavenging activity of compatible solutes. Phytochemistry 1989, 28, 1057-1060.

29. Marklund, S.; Marklund, G. Involvement of the superoxide anion radical in the autoxidation of pyrogallol and a convenient assay for superoxide dismutase. Eur. J. Biochem. 1974, 47, 469-474.

30. Braca, A.; De Tommasi, N.; Di Bari, L.; Pizza, C.; Politi, M.; Morelli, I. Antioxidant Principles from Bauhinia tarapotensis. J. Nat. Prod. 2001, 64, 892-895.

31. Fellegrini, N.; Ke, R.; Yang, M.; Rice-Evans, C. Screening of dietary carotenoids and carotenoidrich fruit extracts for antioxidant activities applying 2,2'-azinobis(3-ethylenebenzothiazoline-6sulfonic acid radical cation decolorization assay. Method. Enzymol. 1999, 299, 379-389.

32. Dorman, H.J.D.; Hiltunen, R. Fe(III) reductive and free radical-scavenging properties of summer savory (Satureja hortensis L.) extract and subfractions. Food Chem. 2004, 88, 193-199.

Sample Availability: Samples of the compounds (Flavonoids and Polysaccharides) are available from the authors.

(C) 2012 by the authors; licensee MDPI, Basel, Switzerland. This article is an open access article distributed under the terms and conditions of the Creative Commons Attribution license (http://creativecommons.org/licenses/by/3.0/). 